\title{
Implementation of Inverse Define Minimum Time Under and Over Voltage Relay
}

\author{
Md. Humayun Kabir Khan *\$, Md Abdullah Al Rakib * \\ * Department of Electrical and Electronic Engineering, Faculty of Engineering, City University-Bangladesh, Dhaka-1216 \\ (humayun10eee@yahoo.com, alrakib108@gmail.com) \\ †Corresponding Author; Md. Humayun Kabir Khan, Dhaka-1216, humayun10eee@yahoo.com
}

Received: 06.05.2021 Accepted:14.06.2021

\begin{abstract}
The key purpose of this project is to invent a mechanism for high/low voltage tripping that will protect against danger. Microcontroller-based relays run rapidly and have less running time. Frequent variations are frequent in the availability of AC mains and the business. A low path of resistance contributes to an extra current flow. Due to multiple causes, irregular over voltages can occur. To secure the load, the tripping function is nice to have. The purpose of our project is to secure electrical devices using an Arduino above and below the voltage. The primary aim of this relay is to isolate the load by monitoring the relay tripping coil with Arduino from the over and under-voltage conditions. It detects any voltage greater than or less than $230 \mathrm{~V}$ $\mathrm{AC}$ (pre-set value). In turn, when the voltage is greater than / less than the current value, it begins a trip signal that is provided to the circuit breaker, then removes the load from the circuit breaker source. Also, for relays, Definite Minimum Time (IDMT) function is used. It is possible to expand this project further to over content relays. As the sum of supply voltage increases, the trip time decreases for reverse time features and the relay operates accordingly. The relay operates on the stated time characteristics only after 5 seconds of failure, regardless of the sum of device voltage. Where the voltage returns to the pre-set value, the relay is reset during relay service (230V AC).
\end{abstract}

Keywords Inverse define minimum time, protective relay, over-voltage, trip time, preset value, definite time.

\section{Introduction}

The power system failure is described as an unexpected condition in the power system. The parameters are unsolicited: short circuit, current leakage, short ground, over current and overvoltage. Today, over-current protection has become a more relevant role. The abnormal over voltages may be caused by sudden heavy load disruption, lightning impulses, pulses of switching, etc. Over-voltage stresses can damage the power system's insulation of different equipment and insulators. Not only for economic reasons but also consumers, the ability of the protection system is required simply to expect "reliable" service. The defensive relay is most commonly combined with the Circuit Breaker relay so that the unstable state in the device can be isolated [1].

Our mission aims to define the under- and overvoltage and to release the load from the mains so that there is no risk to the load. Through manipulating the relay tripping coil with an Arduino, the key function of this relay is to differentiate between load and overvoltage situations. In general, domestic and small commercial loads are secured by fuses and MCBs for overcurrent and no under- and over-voltage protection. The present work aims to build an over and under voltage relay using Arduino at a cheaper cost for domestic and small commercial electrical installations. Any voltage greater than $230 \mathrm{~V} \mathrm{AC}$ is detected (pre-set value). A trip signal is triggered, which is in turn transmitted to the circuit breaker if the voltage is greater than or less than the pre-set value. Then, the circuit breaker isolates the load from the source. Appliances can also be sensed and shielded from high impulse voltages. It is also possible to use the Arduino-based relay circuit as an underovervoltage relay only by adjusting the program's code. It is also possible to employ characteristics such as definite time, inverse, very inverse, incredibly inverse, and many others [8].

The causes are weak protection structures, imbalanced loads, old and obsolete facilities, and power supply deficits rather than demand. The power distribution system is faced with severe faults, states of imbalance, volatility, and forced outages. Voltage spikes and very weak voltage profiles are found in rural regions, in addition to other technological problems. In the summer period and top hour length, customer end voltages usually fluctuate from 20.00 Volts to 220.00 Volts. The reliability and useful life of machinery and home appliances were seriously affected by voltage variations at such a high frequency. A thorough understanding of a fault triggered by the delivery of electricity to the network has always been of vital importance for secure power supply to distribution network operators. 
A rise in any impedance or current would also induce a similar increase in the decrease in voltage. A line's voltage decrease essentially relies on two parameters; these are the line's impedance and the current flowing through the conductor [2].

Operating time with the current is inversely modified in this form of a relay. High-current relays will also operate better than lower relays. With regular opposite, very opposite, and extremely inverse functions, they are available. The running period of both definite-time overcurrent relays and inverse-time overcurrent relays must be modified such that the relay moves closer to the fault before some other security. It is regarded as the grading of time [7].

\section{Literature Review}

Mohamed Zellagui and his team develop a project about the impact of GTO Controlled Series Capacitor (GCSC) parameters on the Inverse Definite Minimum Time (IDMT) (DOCR) centered on the Global Electro technical Commission (IEC) standards. The DOCR is used to secure a single $400 \mathrm{kV}$ transmission system in Algeria's transmission network that connects to the Algerian Company of Electrical and Gas (Group Sonelgaz) [1]. A research considering the designing of the electromechanical and microcontroller (Arduino) based relays an educational lab trainer to compare the behavior of both relays in overcurrent protection of radial feeder which was designed for protection of two sections so that the concept of primary and secondary protection is observed [4]. In their paper, Yin Lee Goh and his team design voltage control modeling for inverse definite minimum time (IDMT) form using DSP panel TMS320F2812 [5].

In this paper, we have proposed a low cost model that detects any voltage greater than or less than $230 \mathrm{~V} \mathrm{AC} \mathrm{(pre-set}$ value). In turn, when the voltage is greater than / less than the current value, it begins a trip signal that is provided to the circuit breaker, then removes the load from the circuit breaker source.

\section{Design of Inverse Definite Minimum Time Relay}

The main objectives of this work are the development of an over-and under-tension relay for domestic and small commercial electrical installations using Arduino at a lower cost, to research the features of instantaneous and IDMTbased under-/over-voltage safety relays, and to evaluate the performance of the IDMT features introduced based on under or over voltage security relays [3].As compared to the acceptable value, the delivery feeder has a higher impedance standard. A detailed line inspection shows that the elevated impedance is caused by poor joints and terminations, hot spots, under-sized conductors, and non-uniform conductor material. In electrical engineering, when a fault is found, a protective relay is a system designed to activate a circuit breaker. A relay is a system that is controlled to affect the operation of other devices in an electric circuit by a difference in its electrical or physical conditions. A defensive relay is a relay with the primary purpose of defending the operation from disruption or avoiding or reducing harm to the apparatus. Electromagnetic instruments, based on coils running on moving parts to track irregular operating conditions such as over-current, over-voltage, reverse power flow, above-and below-frequency, were the first defending relays [9].

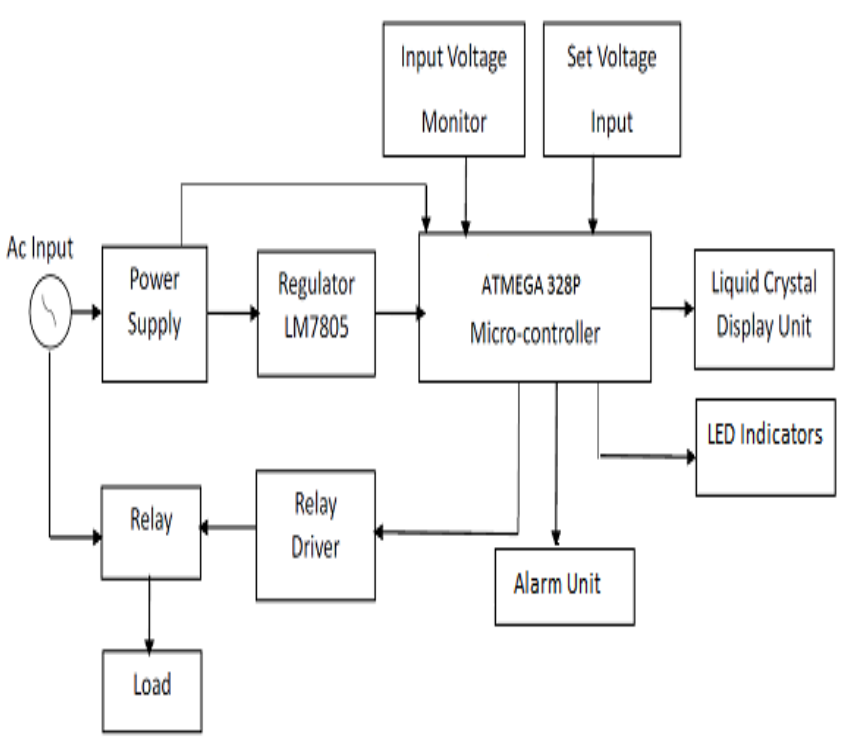

Fig. 1. Functional block diagram of the prototype.

In fig. 1 ac input is the electric utility's input supply where the system can be energized. When the input is within the range of $200 \mathrm{~V}-240 \mathrm{~V}$, it is often provided straight to the relay connections in the system that contacts the load to the source. A step-down transformer is used by the power supply to step down the input mains voltage to a voltage level appropriate for the electronics within the system. To convert the ac voltage to a pulsating dc voltage followed by a filter, a middle tapped transformer with two diodes for maximum wave rectification is used, consisting of a capacitor to filter out (smooth) the pulsation. To provide a controlled $+5 \mathrm{~V}$ supply for the microcontroller, the output voltage is also transferred to an LM7805 positive voltage regulator. The regulator served to further decrease the ripple and noise of the microcontroller's controlled supply. The input voltage sensor provides a accuracy half-wave rectifier track to feed the microcontroller through a potentiometer. The Liquid Crystal Display (LCD) shows the supply voltage and other data at "switch on" or when the voltage is turned on. The supply voltage is beyond the limit of the pre-set limit of values needed. The relay driver is an NPN transistor that reins and deliveries power through the relay coil that links the supply of the mains to the load.

In the $\mathrm{AC} / \mathrm{DC}$ converter half-wave in fig. 2. D3 is open and D1 works when the input signal is positive. The output signal is zero since, with no current through it, one side of R13 is bound to the virtual field. D3 reacts when the feedback is negative, and D1 is open.

In Fig. 3, the circuit diagram of the created system is shown. The circuit was designed and, using Proteus software, its functionality was simulated, The center-tapped transformer TR1 to $12 \mathrm{~V}$ ac at an input mains voltage of $220 \mathrm{~V}$ ac reduces the input mains supply. 


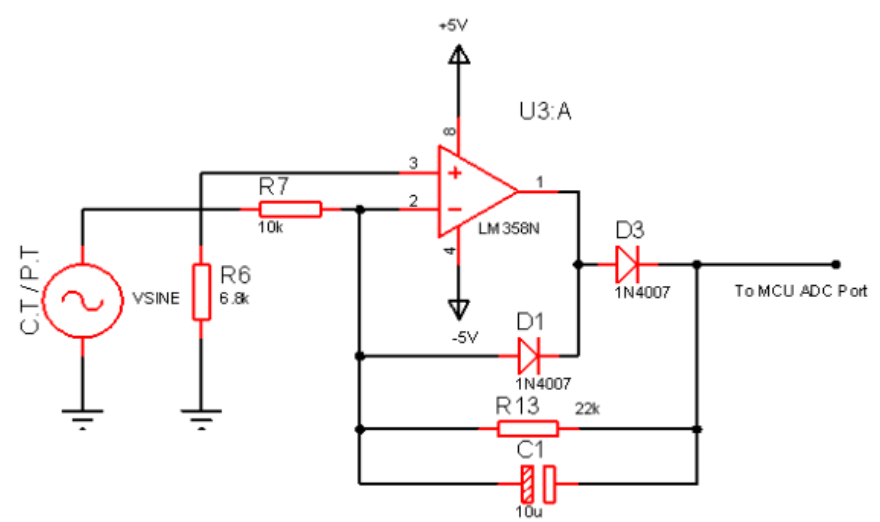

Fig. 2. Circuit diagram of the precision half-wave $\mathrm{AC} / \mathrm{DC}$ converter [11].
The output of TR1 (12V ac) feeds into the precision rectifier circuit according to the circuit diagram, and this voltage is turned into a dc production of the Arduino Uno analog pin A0 that was fed to the rectifier circuit. The device voltage level is indicated by LEDs D3, D4, and D5. BUZ1 has been used for troubling irregular circumstances. Q2 relay driver is used to energize the RL1 relay.

To write machine code and upload this code to the physical board, the Arduino IDE (Integrated Programming Environment) is used. The Arduino IDE is basic and one of the key reasons why Arduino became so popular is probably this simplicity. We may claim that it is now one of the key criteria for a new microcontroller board to be compliant with the Arduino IDE [12]

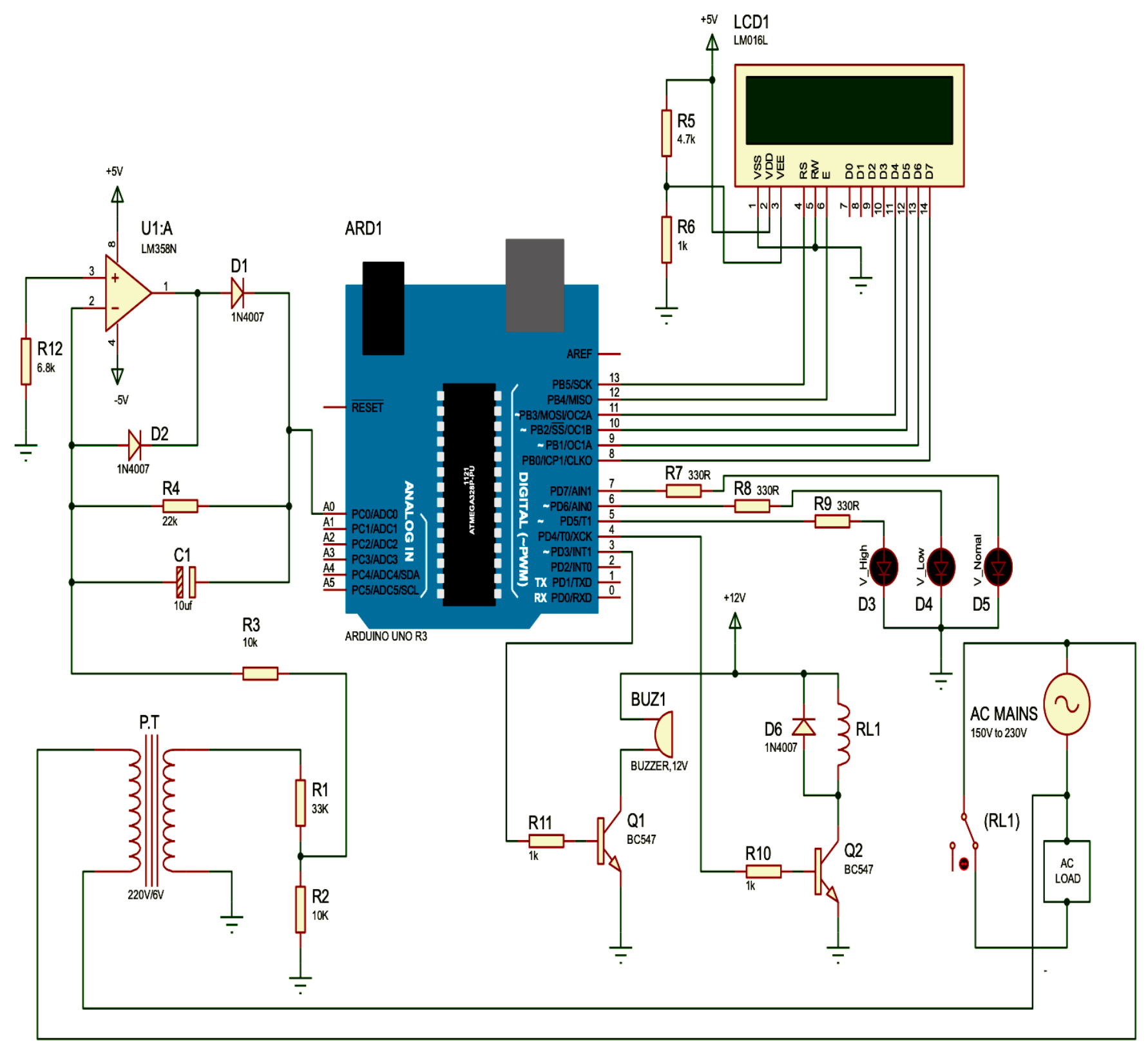

Fig. 3. Circuit of the $\mu \mathrm{C}$-based under and overvoltage protective relay. 


\section{Hardware Simulation with Results}

The configuration and programming were simulated on Proteus software many times before the design code performed satisfactorily until the final microcontroller programming and part assembly for successful design manipulation, the circuit was first bread-boarded and tested to assess satisfactory operation [4]. Based on each point of the design, the device was tested. On the Vero frame, the modules were then assembled and soldered, and then put in a plastic casing. The full and populated circuit boards, along with accessories such as output and input terminals, input control line, switch, liquid crystal display, and indicator lights, were mounted and coupled in the plastic housing. The apparatus is seen in fig. 4 and fig. 5.during the construction time.

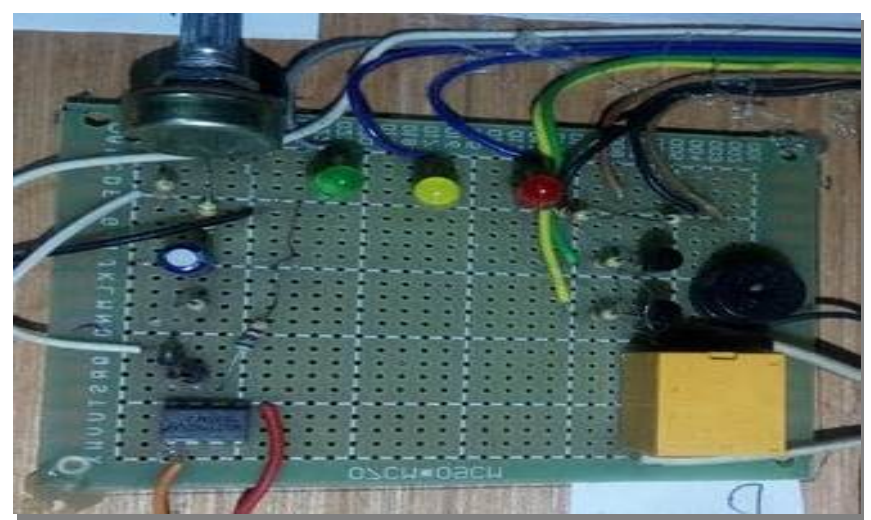

Fig. 4. The complete prototype of the proposed model

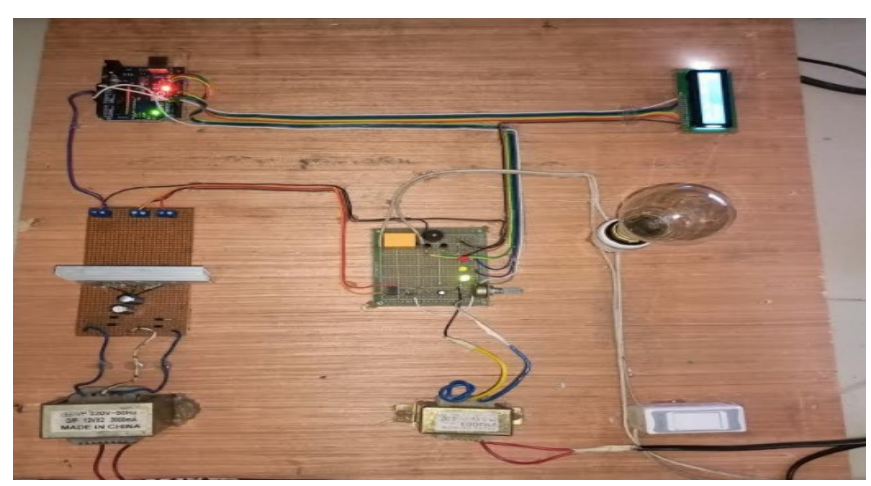

Fig. 5. Precision rectifier, Relay, and LED indicators of the proposed model.

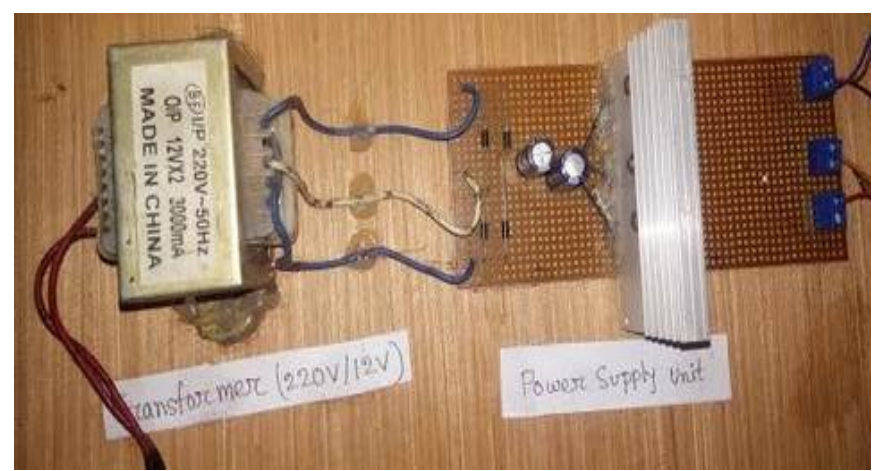

Fig. 6. Power supply unit of the proposed project
Tripping Characteristics is known for IDMT. We have developed a $\mu \mathrm{C}$-based numerical under and over-voltage relay using the given rules.

In the tripping characteristics of IDMT,

Over voltage, $t=\frac{k}{\log (\text { ovf })}$ in sec's.

Under Voltage, $t=\frac{k}{\log (2-u v f)}$ in sec's

Where ' $\mathrm{k}$ ' is the multiplier of time dial setting in steps 0.10 between 0.10 and 1.00 . High time set: ( 0 to 5.00) secs in the under and Over Voltages 4, in steps of $0.10 \mathrm{Sec}$ for IDMT trip features. Time: (0 to 300.0) sec in 1 second steps.

$O v f=\frac{\text { Measured value }}{\text { Set value } \times \text { Rated Voltage }(\mathrm{Un})}$
$U v f=\frac{\text { Measured value }}{\text { Set value } \times \text { Rated Voltage }(\mathrm{Un})}$

Over voltage high set (OVH): $101 \%$ to $130 \%$ of Rating Voltage (Un) in steps of $1 \%$ Defaulting OVH \% set to $120 \%$ of (Un). Over voltage low set (OVL): $101 \%$ to $130 \%$ of Rating Voltage (Un) in steps of 1\% Defaulting OVL \% set to $110 \%$ of (Un). Under voltage high set(UVH): $50 \%$ to $99 \%$ of Rating Voltage (Un) in steps of 1\% Defaulting UVH \% set to 70\%of Un. Under voltage low set(UVL): $50 \%$ to $99 \%$ of Rating Voltage (Un) in steps of $1 \%$ Defaulting UVL \% set to $90 \%$ of (Un)““ [13].

Table 1. When operated in IDMT over-voltage mode

\begin{tabular}{|l|l|l|}
\hline $\begin{array}{l}\text { Source } \\
\text { Voltage(V) }\end{array}$ & $\begin{array}{l}\text { Arduino Voltage } \\
\text { in pin A0 (V) }\end{array}$ & $\begin{array}{l}\text { Trip Time } \\
(\mathrm{Sec})\end{array}$ \\
\hline 245 & 0.71 & 34.62 \\
\hline 255 & 0.74 & 9.69 \\
\hline 267 & 0.77 & 4.93 \\
\hline 284 & 0.80 & 3.09 \\
\hline 290 & 0.82 & 2.75 \\
\hline 307 & 0.88 & 2.10 \\
\hline 325 & 0.91 & 1.69 \\
\hline 351 & 0.95 & 1.34 \\
\hline 380 & 1.02 & 1.10 \\
\hline 420 & 1.15 & 0.91 \\
\hline
\end{tabular}

Table 2. When operated in IDMT under-voltage mode

\begin{tabular}{|l|l|l|}
\hline $\begin{array}{l}\text { Source } \\
\text { Voltage(V) }\end{array}$ & $\begin{array}{l}\text { Arduino Voltage } \\
\text { in pin A0 (V) }\end{array}$ & $\begin{array}{l}\text { Trip Time } \\
(\mathrm{Sec})\end{array}$ \\
\hline 191 & 0.58 & 15.67 \\
\hline 184 & 0.53 & 7.39 \\
\hline 178 & 0.52 & 5.34 \\
\hline 169 & 0.50 & 3.69 \\
\hline 158 & 0.46 & 2.72 \\
\hline
\end{tabular}




\begin{tabular}{|l|l|l|}
\hline 150 & 0.45 & 2.33 \\
\hline 137 & 0.42 & 1.88 \\
\hline 132 & 0.41 & 1.74 \\
\hline 126 & 0.39 & 1.62 \\
\hline 108 & 0.34 & 1.33 \\
\hline
\end{tabular}

Between the table 1 and table 2, Arduino voltage is more in the over voltage mode than the under voltage. In figure 7 the trip time has been gone to high when voltage decreasing in the over voltage mode and in figure 8 as the trip time increasing when the voltage is increasing in the under voltage mode.

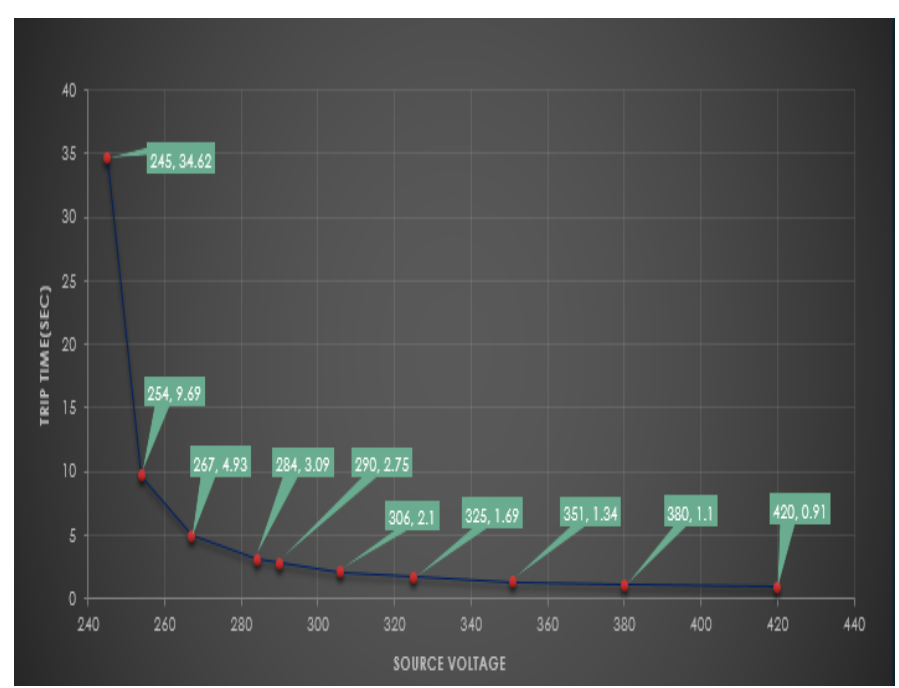

Fig. 7. Graphical representation when IDMT relay operated in the over-voltage mode.

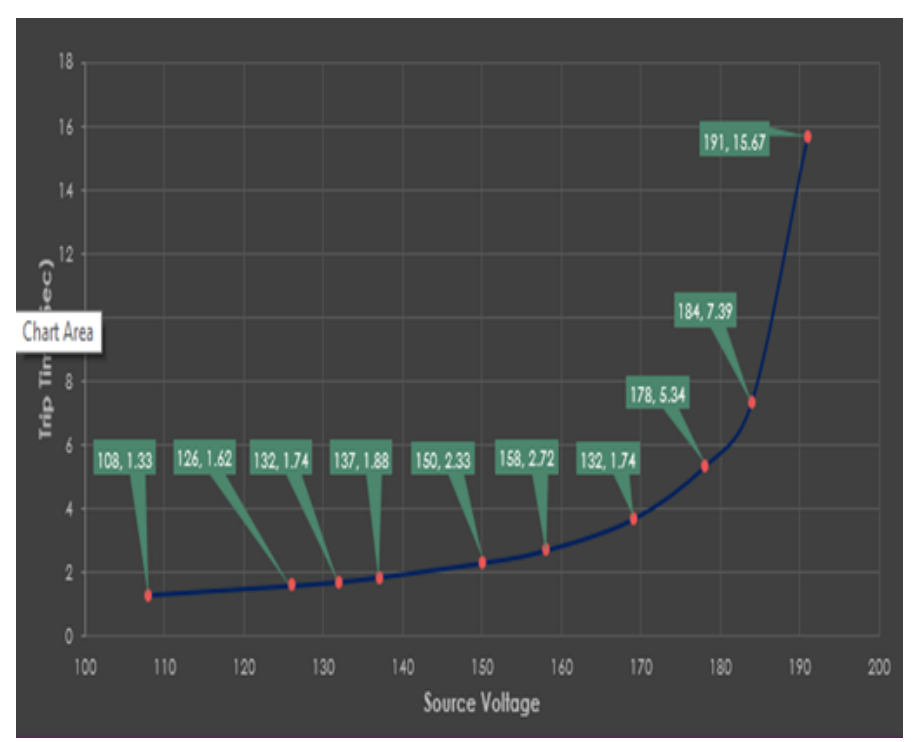

Fig. 8. Graphical representation when IDMT relay operated in the under-voltage mode.

In fig. 8, trip time (sec) as a function of source voltage (V) has given.

\section{Conclusion}

The time of operation of such relays depends on the quantity of actuation. If the volume is very high, the operation of the relay is very easy. In other words, the time of operation of the relays is inversely commensurate with the quantity of the actuation [5]. When the voltage values exceed the set start value of low-set stage $U>$, the overvoltage unit will start to deliver a start signal after a $\sim 60 \mathrm{~ms}$ ' start time. The overvoltage unit will produce a trip signal when the fixed operate time at definite-time characteristic or the measured operate time at inverse definite minimum time (IDMT) characteristic elapses. If the voltage values go beyond the value set in highly specified phase $U \gg>$, the overvoltage device starts providing a start signal after $\sim 50$ meters of start time. The overvoltage section sends a travel indication when the fixed time operates at the definite time feature or the measured working time at the IDMT characteristic elapses. When the voltage values reduction below the set start value of low-set platform $\mathrm{U}<$, the under voltage unit will start to deliver a start signal after a $\sim 80 \mathrm{~ms}$ ' start time. The voltage device delivers a travel signal for the time scheduled to be operated at a certain time characteristic or for the calculation of working time for the IDMT feature elapses.

\section{References}

[1] B. A. Khan, H. M. Ashraf, S. Hamid, R. M. Asif and U. Bashir, "Implementation of Micro Controller Based Electromechanical Over Current Relay for Radial Feeder Protection," 2019 International Conference on Engineering and Emerging Technologies (ICEET), Lahore, Pakistan, 2019, pp. 1-6, doi: 10.1109/CEET1.2019.8711841

[2] Y. L. Goh, A. K. Ramasamy, A. A. Z. Abidin and F. H. Nagi, "Modelling of overcurrent relay using digital signal processor," 2010 IEEE Symposium on Industrial Electronics and Applications (ISIEA), Penang, 2010, pp. 367-370, doi: 10.1109/ISIEA.2010.5679440.

[3] T. Keil and J. Jager, "Advanced Coordination Method for Overcurrent Protection Relays Using Nonstandard Tripping Characteristics," in IEEE Transactions on Power Delivery, vol. 23, no. 1, pp. 52-57, Jan. 2008, doi: 10.1109/TPWRD.2007.905337.

[4] Meraj Hasan, Junaid Maqsood, Mirza QutabBaig, Syed Murtaza Ali Shah Bukhari, Salman Ahmed, "Design \& Implementation of Single Phase Pure Sine Wave Inverter UsingMultivibrator IC," 2015 17th UKSIM-AMSS International Conference on Modeling and Simulation, doi:10.1109/UKSim.2015.58.

[5] S. Sarwar, S. Aslam, W. Arsalan, M. U. Sajjad, A. A. Khan and O. Shami, "Design and Real-Time Implementation of Transformer-less Pure Sine-Wave Inverter," 2020 International Conference on Engineering 
and Emerging Technologies (ICEET), Lahore, Pakistan, 2020, pp. 1-6, doi: 10.1109/ICEET48479.2020.9048200.

[6] D. Lidgate and H. AskarianAbyaneh, "Computer assessment of IDMT relay performance for phase and earth faults on interconnected power systems," IEE Proceedings C (Generation, Transmission and Distribution)

[7] The Basics Of Overcurrent Protection' by 2021 EEP Electrical Engineering Portal[online]. Available:https://electrical-engineering portal.com /download-center/books-andguides/relays/overcu rrentprotection-basics. [Accessed: 08- February- 2021].

[8] Know about Under and Overvoltage Protection Circuit with Working' [Online]. Available:https: //www.elprocus.com/under-and-overvoltage-protectioncircuit/[Accessed: Accessed: 08- February- 2021].

[9] Relay Protection Coordination' by patrarijaya.co.id[online]. Available: https://www.patrarijaya.co.id/relay-protectioncoordination/. [Accessed: 08- February- 2021].

[10] Dual Power Supply Circuit' by theory circuit [online]. Available: https://heorycircuit.com/dual-power-supplycircuit/ [Accessed: 08- February- 2021].

[11] Md. HumayunKabir Khan (Masum) 'PIC Microcontroller Based Automatic Power Factor Correction Using Switched Single Capacitor' by Dhaka University of Engineering \& Technology, Gazipur [online]. Available: https://www.duet.ac.bd/wpcontent/uploads/2019/07/Thesis_-112250P.pdf [Accessed: 08- February- 2021].

[12] Muhammad Ehsan, 'Introduction to Arduino IDE' by MamourDiop\&Congduc Pham [online]. Available: https:/diy.waziup. io/sensors/introduction_Arduino IDE/intro_Arduino_IDE.html/ [Accessed: 08- February2021]. 